\title{
La lucha europea contra la presencia epidémica de la poliomielitis: una reflexión histórica
}

\author{
Rosa Ballester (*) y María Isabel Porras (**) \\ $\left(^{*}\right)$ División de Historia de la Ciencia. Universidad Miguel Hernández. Programa Prometeo de \\ la Generalitat Valenciana (Prometeo2009/122). \\ rosa.ballester@umh.es \\ (**) Facultad de Medicina de Ciudad Real/Centro Regional de Investigaciones Biomédicas \\ (CRIB). Universidad de Castilla-La Mancha. \\ Marialsabel.Porras@uclm.es
}

Dynamis

[0211-9536] 2012; 32 (2): 273-285

\section{La historiografía sobre la polio en Europa (*)}

En 1991, la London School of Hygiene and Tropical Medicine fue la sede de un importante encuentro de expertos europeos en salud pública y políticas sanitarias que, bajo el título de Europe without frontiers: the implications for health ${ }^{1}$, pretendía responder a los retos que el nuevo mapa político surgido tras la caída del muro de Berlín y sus consecuencias, planteaban en el Continente. En un ambiente de claro optimismo, se hacía explícita la necesidad de avanzar en el camino de unas políticas europeas comunes de salud, por encima de barreras nacionales, lo que llevaba consigo un cambio de mentalidad y una visión unitaria para hacer frente a los problemas, siendo conscientes de que en la práctica, los dos proyectos en los que todos los estados europeos estaban implicados («Ciudades Saludables» y «Salud para Todos»), se debían a la coordinación realizada por la Oficina Regional para Europa de la Organización Mundial de la Salud y a los esfuerzos para superar

$\left(^{*}\right)$ Artículo realizado en el marco de los proyectos de investigación Pll1109-0114-0843 (financiado por la Consejería de Educación y Ciencia de la JCCM) y HAR2009-14068-C03-01/HIST (financiado por el MICINN).

1. Normand, Charles E. M.; Vaughan, J. Patrick, eds. Europe without frontiers: the implications for health. Chichester: John Wiley and Sons, 1993. 
el freno que para alcanzar cotas más altas de integración representaban las diferentes tradiciones, modos y acercamientos nacionales.

Cincuenta años antes de este encuentro multinacional, un problema acuciante, con graves repercusiones físicas, sociales y psicológico-sociales, golpeaba a diversos países europeos y de otros continentes, cebándose, de modo preferente en el estrato más vulnerable de la sociedad: la infancia. La aparición de la poliomielitis como enfermedad de comportamiento epidémico fue una novedad a partir de las primeras décadas del siglo XX y la inexistencia de un tratamiento y/o prevención eficaces producía sentimientos de miedo, especialmente por las graves secuelas motoras de las formas paralíticas de la enfermedad y por su distribución nada previsible ya que no se veía relacionada con lo que había sido la norma para el resto de las enfermedades infecciosas: la falta de higiene y las malas condiciones de vida. La grave epidemia de Copenhague de 1952 y las noticias que llegaban del otro lado del Atlántico, significaban la constatación de que no había fronteras ni grupos sociales inmunes y que la globalidad de la enfermedad en el mundo occidental, era una realidad palpable.

¿Cuáles fueron las respuestas, si las hubo, a este importante reto por parte de los países europeos? Los estudios que han abordado esta cuestión para Europa son todavía escasos, ya que, a diferencia de lo ocurrido en los EEUU o en Canadá, la historia de la poliomielitis en Europa ha permanecido prácticamente inexplorada hasta el siglo XXI. La proximidad de su erradicación en este marco geográfico, anunciada el 21 de junio de 2002, estimuló la realización de investigaciones centradas en el continente europeo.

El dossier que presentamos tiene un doble punto de partida. Por un lado, pretende cubrir un hueco importante como acabamos de comentar, las escasas aportaciones historiográficas relativas a una de las enfermedades con mayor grado de repercusión social en la región europea de las primeras seis décadas del siglo XX, la parálisis fláccida o poliomielitis, frente a la atención preferente dada en otros ámbitos geográficos, en especial, el norteamericano hasta tal punto que es un tópico decir que la polio es una de las enfermedades más y mejor estudiadas de todas las que en Norteamérica se han dado. De hecho, en Estados Unidos y Canadá la difusión de los trabajos sobre historia de la polio ha sobrepasado con holgura los públicos académicos para difundirse a entornos sociales mucho más amplios. Un ejemplo paradigmático es el de la concesión de un Premio Pulitzer a un trabajo sobre la historia de la polio en Estados Unidos o el interés despertado por la reciente aparición y el éxito editorial extraordinario de la obra 
de Philip Roth, Nemesis ${ }^{2}$. En segundo término, la idea del dossier partió de la doble hipótesis de que, en el afrontamiento de la enfermedad, especialmente en el periodo posbélico y posterior — décadas de 1940 a 1970_ las trayectorias seguidas por los distintos países europeos fueron muy diversas dependiendo de cuestiones políticas (Guerra Fría, regímenes dictatoriales y democracias), económicas y culturales; pero que también se dio una respuesta europea, más o menos articulada que marcó, de algún modo, las políticas nacionales frente a la enfermedad. Esta idea iba ganando terreno conforme avanzábamos en el conocimiento del proceso en los distintos países, así como sobre los diferentes sistemas de coordinación e intercambio entre ellos y con los organismos internacionales públicos (Organización Mundial de la Salud) y privados (National Foundation for Infantile Paralysis). Como ejemplo, dos títulos recientes: el artículo de Lindner y Blume ${ }^{3}$, centrado en la introducción de las vacunas frente a la poliomielitis en Reino Unido, República Federal de Alemania y Holanda; y la parte correspondiente a la región europea en la monumental obra coordinada por Smallman-Raynor y Cliff ${ }^{4}$, además de los estudios previos realizados en Escandinavia ${ }^{5}$ y en España ${ }^{6}$, que parecían también apuntar claramente en esta dirección.

El dossier pretende, pues, presentar la experiencia europea, en sus peculiaridades e identidades propias que la diferencian de la llevada a cabo

2. Oshinsky, David M. Polio. An American story. Oxford-New York: Oxford University Press; 2005; Roth, Philipp. Nemesis. New York: Houghton Mifflin Harcourt Pub. Co.; 2010.

3. Lindner, Ulrike; Blume, Stuart. Vaccine innovation and adoption: polio vaccines in the UK, the Netherlands and West Germany, 1955-1965. Medical History. 2006; 50 (4): 425-446. La peculiaridad del abordaje de la polio en el Reino Unido ha sido analizada por Hardy, Anne. Poliomyelitis and the neurologists, the view from England, 1886-1996. Journal of the History of Medecine. 1997; 71 (2): 249-272.

4. Smallman-Raynor, Matthew; Cliff, Andrew, eds. A world geography. Emergence to eradication. Oxford: Oxford University Press; 2006.

5. Axelsson, Per. Höstens spöke. De svenska polioepidemiernas historia. Stockholm: Carlsson; 2004 [Swedish text with a summary in English, p. 230-238]. Axelsson, Per. «No os comáis esas manzanas; jhan estado en el suelo!»: la epidemia de polio y las medidas preventivas en Suecia, desde la década de 1880 hasta la década de 1940. Asclepio. 2009; 61 (1): 23-38

6. Báguena, María-José. Estudios epidemiológicos y virológicos sobre la poliomielitis en Valencia (1959-1969). Asclepio. 2009; 61 (1): 39-54; Ballester, Rosa; Porras, María-Isabel. El significado histórico de las encuestas de seroprevalencia como tecnología de laboratorio aplicada a las campañas de inmunización. El caso de la poliomielitis en España. Asclepio. 2009; 61 (1): 55-80; Rodríguez Sánchez, Juan Antonio; Seco Calvo, Jesús. Las campañas de vacunación contra la poliomielitis en España en 1963. Asclepio. 2009; 61 (1): 81-116; Martínez Pérez, José. Presentación: la poliomielitis como modelo para el estudio de la enfermedad en perspectiva histórica. Asclepio. 2009; 61 (1): 7-21. 
en otros lugares como Estados Unidos, a través de uno de los aspectos de mayor relieve: el tema de las vacunaciones, merecedor de un estudio de mayor alcance del cual el presente número de Dynamis solo persigue ser un avance $^{7}$. Los años iniciales del desarrollo de las vacunas antipoliomielíticas estuvieron caracterizados no solo por el enfrentamiento personal entre Jonas Salk (quien había desarrollado un tipo de vacuna con virus inactivados en la universidad de Pittsburg) y Albert Sabin (quien obtuvo una vacuna con virus vivos atenuados en la universidad de Cincinnati), sino también por las discusiones de científicos en los diversos países en torno a las ventajas e inconvenientes de una u otra modalidad. La justificación de situar el conjunto de aportaciones del presente dossier en varias dimensiones, pero especialmente en el tema de las vacunas, viene dada por el hecho de que fue esta cuestión el núcleo fundamental de las actividades llevadas a cabo en la lucha frente a la enfermedad y en torno al cual se produjeron las principales discusiones científicas sobre su eficacia e inocuidad, sobre el tipo de vacuna más adecuado, su repercusión económica o la existencia o no de tecnologías apropiadas para producir vacunas en uno u otro país europeo. Asímismo, las campañas de inmunización masiva representan un campo de pruebas idóneo tanto para el análisis histórico de la puesta en marcha de los instrumentos de propaganda sanitaria institucional como para el estudio de las propias políticas sanitarias nacionales.

\section{De la emergencia a la erradicación de la poliomielitis en Europa}

La poliomielitis, que había acompañado endémicamente a la humanidad desde la Antigüedad, emergió como una enfermedad epidémica a finales del siglo XIX, primero en Europa (1881) y la década siguiente en los EEUU y en Canadá. Ese momento marcó el inicio de la historia de la polio como un problema de salud pública que para el continente europeo finalizó en 2002, año de su erradicación. Smallman-Raynor y Cliff, combinando hitos epidemiológicos con fechas clave en la lucha contra la enfermedad ${ }^{8}$, han

7. Los estudios históricos sobre las vacunas contra la polio se han centrado generalmente en los EEUU, donde se desarrollaron las vacunas, habiéndose prestado escasa atención a su introducción y aplicación en Europa. Lindner; Blume, n. 3.

8. Los años 1955, 1988 y 2002 se corresponden, respectivamente, con las fechas en las que estuvo disponible la primera vacuna contra la polio, se produjo la resolución de la $41^{\text {a }}$ Asamblea de la OMS sobre la erradicación global de la enfermedad y la declaración oficial de su erradicación en Europa. 
dividido esa historia en cuatro etapas: $1^{\text {a }}$ ) de «emergencia epidémica de la enfermedad (1880-1920)»; $2^{a}$ ) de «expansión global (1921-1955)»; $\left.3^{a}\right)$ de «retirada global (1955-1988)», y $\left.4^{\mathrm{a}}\right)$ de «erradicación global (1988-2002)»9 .

Como se ha adelantado, la emergencia epidémica de la polio arrancó con la epidemia de 1881 del noroeste de Suecia, que dio paso a sucesivos brotes epidémicos de magnitud creciente, limitados inicialmente a Escandinavia, aunque ocasionalmente afectaron también a Italia (1883), Alemania (1884) y Francia (1885). Durante la década final del siglo XIX la intensidad epidémica de la polio se multiplicó y alcanzó mayor extensión europea. Se produjeron las primeras epidemias en Inglaterra y Gales (1896), España (1896) y Austria (1897), pero también en los EEUU y Canadá. La expansión europea y norteamericana de las epidemias de polio se acentuó en la primera década del siglo XX, registrándose la transición desde pequeños brotes epidémicos con menos de veinticinco casos a otros más graves con más de cien casos. Una expresión de esta nueva dinámica fue la importante epidemia de 1905 ocurrida en Suecia y Noruega, que tuvo su correlato dos años más tarde en los EEUU y cuatro después en Austria y Alemania. Estas primeras experiencias epidémicas generaron un importante corpus de conocimiento sobre la polio, fruto fundamentalmente de investigaciones de médicos escandinavos. A uno de ellos, el sueco Ivar Wickman, se debe la idea de la naturaleza infecciosa de la enfermedad, la importancia del aislamiento de los enfermos y de las desinfecciones de heces y fosas nasales como medidas de lucha, pero también la constatación de la dificultad de realizar correctamente el aislamiento por la existencia de portadores sanos y casos abortivos, que él identificó con motivo de la epidemia de $1905^{10}$.

La segunda década del siglo XX comenzó con nuevas y más graves epidemias en Escandinavia, que, a diferencia de las anteriores, tuvieron mayor repercusión en las grandes ciudades suecas que en las zonas rurales. Los brotes fueron también importantes en Inglaterra y Gales, en donde la polio se convirtió en enfermedad de declaración obligatoria el 1 de septiembre de 1912.

Esta nueva ola epidémica tuvo asimismo su correlato en parte de la Europa continental (Austria, Prusia...) y estimuló investigaciones como la que Ramón Gómez Ferrer, catedrático de Pediatría en la Facultad de Medicina de la Universidad de Valencia y Jefe del correspondiente servicio

9. Smallman-Raynor; Cliff, n. 4.

10. Smallman-Raynor; Cliff, n. 4, p. 93-102; Paul, John Rodman. A history of poliomyelitis. New Haven-London: Yale U.P.; 1971, p. 94. 
del Hospital Provincial de Valencia, presentó en el III Congreso Español de Obstetricia, Ginecología y Pediatría en $1913^{11}$. En ella este pediatra expuso los resultados del estudio que había realizado sobre la distribución geográfica de la poliomielitis (denominada aún parálisis espinal infantil) en ciudades y pueblos de la región de Valencia, que mostraba que esta enfermedad había sido esporádica en España entre 1893 y 1909, y se había convertido en epidémica entre 1910 y 1912. A la vista de estos resultados, Gómez Ferrer juzgaba necesario solicitar al Gobierno que la poliomielitis se incluyera dentro de las enfermedades de declaración obligatoria, situación que se produjo tres años más tarde con la promulgación de la Real Orden del 14 de diciembre de 1916, coincidiendo con la grave epidemia registrada en Nueva York ese mismo año. El cumplimiento de dicha Real Orden fue escaso, incluso tras ser añadida en 1919 a la lista de enfermedades infecciosas de declaración obligatoria de la Instrucción General de Sanidad de 1904. De hecho, no se contó con información más fiable del número de casos de polio en España hasta la creación del Servicio Epidemiológico Central el 29 de noviembre de 1927, dentro de la Dirección General de Sanidad, que contó con financiación de la Fundación Rockefeller ${ }^{12}$.

Con la puesta en marcha del citado Servicio Epidemiológico Central, que propició el uso progresivo de la estadística en el campo de la epidemiología ${ }^{13}$, España seguía las directrices marcadas por el Comité de Higiene de la Liga de Naciones en los años posteriores a la I Guerra Mundial para disponer de medios que facilitaran un rápido intercambio de información epidemiológica sobre las enfermedades de declaración obligatoria, como era el caso de la poliomielitis aguda y la polioencefalitis aguda. Aunque persistía el subregistro de los casos de polio, la modernización acometida

11. Gómez Ferrer, Ramón. Parálisis espinal infantil. Etiología y patogenia. In: Actas III Congreso Español de Obstetricia, Ginecología y Pediatría Valencia. Valencia; 1913, p. 210-293.

12. Martínez Navarro, Ferrán; Larrosa, Alberto; Páez, Adela. Estudio de la epidemia de poliomielitis infantil presentada en Madrid durante el año 1929 por el Dr. Laureano Albadalejo. Primera memoria anual de los trabajos llevados a cabo por el Servicio Epidemiológico Central (1929). In: Martínez Pérez, José et al. La medicina ante el nuevo milenio. Una perspectiva histórica. Cuenca: Ed. UCLM; 2004, p. 963-987. Rodríguez-Ocaña, Esteban. La salud pública en la primera mitad del siglo XX. In: Atenza, Juan; Martínez Pérez, José, eds. El Centro secundario de higiene rural de Talavera de la Reina y la sanidad española de su tiempo. Cuenca: Junta de Comunidades de Castilla La Mancha; 2001, p. 21-42.

13. Rodríguez-Ocaña, n. 12. Marset, Pedro; Rodríguez-Ocaña, Esteban: Sáez, José Miguel. La salud pública en España. In: Martínez Navarro, Ferrán et al. Salud pública. Madrid: Mac Graw-Hill Interamericana; 1998, p. 25-47. 
permitió una mejor evaluación de las nuevas epidemias que se sucedieron en el período de entreguerras y constatar la expansión global de la enfermedad y el papel que la II Guerra Mundial desempeñó en ello.

A las epidemias de los años veinte, siguieron las de los treinta -más extensas e intensas a partir de 1936- y sobre todo las de la segunda mitad de los años cuarenta y comienzo de los cincuenta, que marcaron una nueva fase en la magnitud y extensión de la actividad de la polio en Europa, alcanzando también a los países del Sur. Responsable de esta transformación epidémica fue, sin duda, el conjunto de factores y circunstancias que concurrieron entre ambas contiendas mundiales. Las condiciones sociales, económicas, políticas y los conflictos bélicos motivaron movimientos masivos de población civil. Se ha destacado la importancia que, durante la II Guerra Mundial, poseyeron estos movimientos, especialmente las concentraciones infantiles en escuelas superpobladas con malas condiciones higiénicas, y sus desplazamientos desde zonas urbanas a las rurales ante la amenaza de bombardeos, por cuanto provocaron la ruptura del equilibrio ecológico existente y facilitaron un aumento de la actividad de la polio en los lugares de recepción. También se ha señalado el papel que habrían desempeñado la pobre alimentación, el racionamiento, el deterioro de las condiciones de vida y la importación de nuevas y, quizás, más virulentas cepas de virus con el retorno de los soldados europeos que habían estado destinados fuera del continente europeo. De hecho, todos estos han sido los factores esgrimidos para explicar la gravedad y extensión alcanzada por las epidemias de Inglaterra, Gales, Irlanda o Berlín occidental en $1947^{14}$. Éste fue el primero de los grandes brotes ocurridos entre la II Guerra Mundial y el comienzo de las vacunaciones masivas en 1955, que, como muestra el artículo de Porras, Báguena, Ballester y de las Heras que abre este monográfico, motivó además que se dieran los primeros pasos para la creación de la Asociación Europea contra la Poliomielitis (AEP) y se solicitara para ello el apoyo de la OMS en su II Asamblea General.

Probablemente, la institución más representativa de los intentos de buscar estrategias de coordinación europeas de tipo global para enfrentarse a la enfermedad, es la estudiada en el artículo citado arriba: la Asociación Europea contra la Poliomielitis. Entre 1951 y 1969, la AEP dio visibilidad a la respuesta europea, puso sobre el tapete la dimensión real de la polio- 
mielitis y fue un foro de encuentro privilegiado y multidisciplinar donde compartir problemas y experiencias, lo que no excluyó la existencia de puntos de vista diferentes sobre el cómo lograr el objetivo común de acabar con la poliomielitis. El papel de la AEP, apoyada por la National Foundation for Infantile Paralysis y, sobre todo, por la OMS, en la búsqueda de una vía europea de lucha contra la polio mediante el diseño y establecimiento de los programas europeos de vacunación, es analizado en detalle en este trabajo, que revela el extenso e intenso debate ocurrido en su seno sobre las cualidades de ambas vacunas. El artículo muestra la evolución de las diversas posturas hasta imponerse la que defendía que la vacuna Sabin era la apropiada para realizar las vacunaciones masivas y conseguir la erradicación de la enfermedad ${ }^{15}$. En efecto, las inmunizaciones masivas con vacuna oral iniciadas en 1960 se acompañaron de una espectacular reducción del número de casos de polio y de la retirada global de esta enfermedad de los países europeos a medida que éstos emprendían las campañas de vacunación generalizadas, aunque también es cierto que se logró igualmente la erradicación de la enfermedad en Suecia o Finlandia con el empleo exclusivo de vacuna tipo Salk.

La presencia de científicos europeos de mayor prestigio procedentes de diversas áreas (virólogos, inmunólogos, clínicos, pediatras o epidemiólogos) en los doce Symposia de la AEP, propició que las discusiones científicas fueran de muy alto nivel, que el intercambio de experiencias se hiciera desde unos estándares de gran rigor y que se adoptaran consensos importantes, por ejemplo, sobre la vigilancia de los programas europeos de vacunación que ponía las bases para lo que a principios del siglo XXI, se hacía realidad oficialmente con la acreditación, por parte de la OMS, de la erradicación de la enfermedad en la Región Europea. La puesta a punto de la vacuna con virus muertos de Salk, primera vacuna efectiva contra la polio, proporcionó un instrumento eficaz para luchar contra este importante problema de Salud Pública y abrió la puerta hacia su control y posterior erradicación, objetivo adoptado en 1984 por el Comité de la Oficina Regional de la OMS para Europa, que se consiguió en 2002, pero que aún no se ha logrado a nivel mundial, a pesar del compromiso adquirido por la OMS tras la resolución de la $41^{\text {a }}$ Asamblea General en 1988.

15. El efecto de estos debates en el cambio de posición de los científicos y sanitarios de la República Federal Alemana ha sido señalado en Lindner; Blume, n. 3, p. 433. 


\section{Políticas nacionales y campañas de vacunación}

El análisis histórico comparado de las respuestas nacionales al desarrollo y aplicación efectiva de los dos grandes tipos de vacunas antipoliomielíticas, nos ayuda a entender cómo unos mismos datos de laboratorio o de tipo epidemiológico, pueden ser interpretados de forma muy diferente $y$, por tanto, fuera de la pretendida objetividad de los datos científicos que proporcionaban los expertos a los responsables políticos. Así, los datos epidemiológicos y de laboratorio no fueron siempre determinantes a la hora de adoptar unas determinadas políticas sanitarias frente a la poliomielitis. Conocemos bien, a través del excelente trabajo de Lindner y Blume $^{16}$ cómo en Inglaterra y Gales, en la República Federal Alemana y en Holanda - donde se produjeron brotes epidémicos de similar magnitudlos poderes públicos respondieron de forma muy diferente a la noticia de la aparición de las vacunas de Salk y Sabin. Las tradiciones y las particulares circunstancias políticas, económicas, científicas y sanitarias de cada país europeo condicionaron el inicio de la vacunación, su ritmo y extensión, la utilización de vacuna de fabricación propia o importada y el tipo de vacuna empleado. Las diversas experiencias nacionales y los debates suscitados en torno a estos temas, muy especialmente respecto a la validez de las vacunas Salk o Sabin y a la superioridad de una de ellas frente a la otra, quedaron bien reflejados en los Congresos Internacionales sobre la polio, las reuniones organizadas por la OMS y los Simposios de la Asociación Europea contra la Polio celebrados entre 1951 y 1969.

En Holanda, la vacuna tipo Salk fue introducida de forma rápida y con mucho éxito en 1956, solo un año más tarde del gran ensayo clínico hecho en Estados Unidos por Thomas Francis. Por el contrario, en Inglaterra y Gales la introducción de la citada vacuna se retrasó por espacio de más de dos años y fue gradualmente sustituida por la vacuna oral Sabin. Finalmente, en la República Federal Alemana, la vacuna tipo Salk entró muy tarde y con pobres resultados. Intentando dar respuestas al porqué y al cómo de estas diferencias, Lindner y Blume encuadran sus datos en el marco teórico de los estudios sobre historia de las innovaciones médicas ${ }^{17}$ y subrayan tres factores que resultan determinantes para explicar la situa-

16. Lindner; Blume, n. 3.

17. Schlich Thomas; Tröhler Ulrich, eds. The risk of medical innovation, risk perception and assesment in historical context. Abingdon-New York: Routledge; 2006. 
ción: 1) la diferente organización de los sistemas sanitarios; en aquellos más centralizados, como era el caso del National Health Service británico, la adopción de las novedades tecnológicas era un poco lenta pero, una vez tomada la decisión política, la difusión era muy rápida. La República Federal Alemana, con un débil y fragmentado sistema de salud pública, aunque contara con un esquema consolidado de asistencia médica, no tenía la estructura más adecuada para la citada difusión; 2) la posibilidad de crear en el propio país un número elevado de dosis que permitiera emprender vacunaciones en masa en un corto periodo de tiempo, era la segunda de las variables. Los laboratorios alemanes y británicos se veían desbordados para poder suministrar la cantidad de dosis necesarias de vacunas de calidad. En cambio, Holanda, un país mucho más pequeño, contaba con una institución estatal de producción de vacunas que permitía pudieran ser utilizadas en el programa nacional de vacunación holandés; 3) las diferentes actitudes frente a las vacunas por parte de los propios científicos, sobre todo tras el escándalo que supuso el conocimiento del llamado «incidente Cutter», que provocó la polio paralítica a algunos de los niños vacunados. Tras el ensayo exitoso realizado por Salk en los EEUU comenzó la utilización $-\mathrm{y}$, en ocasiones, también la fabricaciónde dicha vacuna en algunos países europeos, pero el «incidente Cutter» interrumpió momentáneamente las vacunaciones iniciadas o retrasó su inicio en aquellos países en los que aún no habían comenzado, hasta que se relacionó dicho incidente con algunos problemas técnicos en el proceso de filtración del virus.

El caso Cutter es, precisamente, el evento del que se sirve Per Axelsson para acercarnos a la peculiaridad del caso sueco. Siguiendo un larga tradición de investigadores suecos como Karl-Oskar Medin o Ivar Wickman, autores de referencia obligada en la historia de la enfermedad, desempeñó un papel decisivo la importante figura de Sven Gard, no solo en su propio país sino a nivel internacional como destacado experto en temas de poliomielitis. De hecho, en fechas paralelas a los trabajos de Salk en Pittsburg, el grupo de Gard experimentaba con un tipo de vacuna inactivada, solo que, a diferencia del revuelo mediático que la vacuna de Salk había desencadenado en Estados Unidos, los investigadores suecos fueron mucho más cautelosos para no despertar falsas esperanzas en la población hasta que la evidencia científica en cuanto a los resultados de la vacuna fuera muy sólida. Y reflejo de esta actitud fue, como indica Axelsson, el estilo de comunicar la información a través de medios como la radio y el periodismo escrito. 
Bernardino Fantini nos acerca en su artículo a uno de los países en los que los brotes epidémicos coinciden en el tiempo con un periodo político complejo, que incluye desde el fascismo a la formación y desarrollo de la República italiana. La creación de instituciones oficiales y actividades privadas, evolucionó en paralelo con el recrudecimiento de la enfermedad y la incorporación de investigadores y clínicos italianos al estudio de la polio fue muy importante, siendo un reflejo de la misma los contenidos y la organización de una de las conferencias internacionales sobre poliomielitis celebrada en Roma en 1954, en un momento especialmente grave tras la epidemia de 1947 que afectó prácticamente a todos los países occidentales. Este fue también el año en el cual se publicó el primer informe del Comité de Expertos de la OMS sobre poliomielitis y momento crucial inmediatamente anterior a la puesta en marcha de las vacunas. La elección de la capital italiana para la celebración de este encuentro internacional hay que entenderla, tal y como Fantini indica, con la apertura de la comunidad científica y médica italiana al exterior tras la caída del fascismo y la mejora de la situación económica iniciada tras la ayuda internacional a través del Plan Marshall. La conferencia de Roma fue fundamental para trazar una agenda global e incluir en ella todos los aspectos científicos y médico-sociales relativos a la enfermedad. La puesta en marcha de las campañas de vacunación hay que interpretarla también en el contexto de la estructura y dinámica del sistema de salud pública italiano y del intercambio de experiencias con otros países. Finalmente, las políticas con respecto a la polio estuvieron claramente influídas por los cambios experimentados en la transición del periodo fascista a la Italia de la Posguerra con la creación de nuevas instituciones como un Alto Commisariato per l'Igiene e la Sanità Pubblica, encargado de coordinar tanto los aspectos asistenciales como preventivos, incluido un Istituto Superiore di Sanità al que se le encomendaron tareas de formación y de investigación epidemiológica, fundamentales para la lucha contra la poliomielitis en el país.

\section{El asociacionismo europeo en torno a la poliomielitis}

El dossier recoge también un aspecto de gran interés como son las experiencias europeas en torno a los movimientos asociativos. La presencia del síndrome postpolio a partir de la década de 1980-90, es sin duda la causa más directa del elevado número de asociaciones de afectados de polio y 
síndrome post-polio tanto en Europa como en otros muchos países. La European Polio Union (EPU) creada en 2006 y con sede en Copenhague, representa la parte más visible de este intento de coordinar esfuerzos y buscar vías comunes europeas, también en este tema, promoviendo políticas de cambio en la consideración y en las realizaciones prácticas para este tipo de personas con una peculiar discapacidad física. Si la EPU representa una novedad en cuanto a la creación de una red europea de asociaciones de polio y síndrome postpolio, su puesta en marcha no puede entenderse sin analizar las raíces históricas de este proceso en los diferentes países. En efecto, la intensificación y extensión de las epidemias de polio estimularon también el desarrollo del asociacionismo de las personas afectadas por esta enfermedad y sus secuelas desde los años treinta del pasado siglo. El dossier contiene información sobre el particular en los casos italiano -en el capítulo de Fantini- y sueco - en el de Axelsson- pero, además, hay dos contribuciones centradas específicamente en este tema. Por un lado, el trabajo de Barry North, archivero e historiador de la British Polio Fellowship (BPF), donde se analiza el papel pionero de dicha organización -de personas con discapacidad y no para personas con discapacidad-desde su fundación en 1939 hasta la actualidad, y muestra los cambios registrados para adaptarse a las circunstancias cambiantes como la aparición en los años ochenta del siglo XX del Síndrome Postpolio. El análisis comparado de la organización británica con la todopoderosa y coetánea National Foundation for Infantile Paralysis, que tuvo entre sus mentores al propio presidente de los Estados Unidos Theodor Roosevelt, resulta de gran interés para estudiar sus diferencias marcadas por el tipo de sociedad y de tradición cultural entre ambos países.

Por otro lado, el trabajo de Juan Antonio Rodríguez Sánchez nos acerca al desarrollo del movimiento asociativo en España entre 1957 y 1975 - muy vinculado a la Iglesia Católica y a las especiales circunstancias políticas e ideológicas del periodo estudiado- y su relación con las personas afectadas por polio. El estudio de dos de las asociaciones: La Fraternidad y la Asociación de Lucha contra la Poliomielitis (ALPE), le sirve al autor para reconstruir no solo las actividades y medios de difusión de las mismas, bien diferentes en la forma de entender y abordar los problemas, sino también para desvelar actitudes sociales y estereotipos de la discapacidad, así como el papel que ambas instituciones desempeñaron en la creación, en un tiempo y lugar nada favorables, de espacios de sociabilidad, de promoción personal y de visibilidad. 
El conjunto de aportaciones del dossier - sin ninguna pretensión de exhaustividad - constituyen un primer acercamiento de conjunto a algunas de las experiencias europeas frente a la polio y puede servir también como estímulo para, por un lado, profundizar en temas de investigación apenas esbozados aquí como los procelosos itinerarios seguidos por los afectados a través de las intervenciones quirúrgicas múltiples y de la rehabilitación o sus experiencias de vida. Por otra parte, el análisis comparado con lo sucedido en otros entornos geográficos, especialmente relevantes como el Iberoamericano.

\section{Agradecimientos}

Las coordinadoras del monográfico desean manifestar su agradecimiento a María José Báguena por el inestimable apoyo prestado en el proceso de edición del mismo, así como a Josep Bernabeu, Jon Arrizabalaga, Esteban Rodríguez-Ocaña y a los/as evaluadores/as anónimos/as por las sugerencias y revisiones realizadas. 